Mr Zvonko Radosavljević, dipl. inž Vojnotehnički institut Beograd

\section{ANALIZA GREŠKE U ALGORITMIMA ZA PRAĆENJE POKRETNIH CILJEVA PRIMENOM ALGORITMA GNN}

UDC: $621.396 .969 .3: 004.421$

Rezime:

Izbor podesnog algoritma u skladu sa raspoloživim računarskim resursima važna je karika u lancu otkrivanja i praćenja pokretnih ciljeva pomoću osmatračkog radara. Efikasnost ovih algoritama zavisi od izbora estimatora stanja, položaja i brzine i metode za asocijaciju podataka. U radu je analizirana greška praćenja 20 ciljeva pomoću algoritma ,najbližeg suseda" (GNN). Za estimaciju stanja korišćen je Kalmanov filter i algoritam IMM. Mera kvaliteta praćenja je srednja kvadratna greška po poziciji. Za simulaciju praćenja odabrane su putanje leta četiri grupe po pet ciljeva sa i bez manevra.

Ključne reči: praćenje pokretnih ciljeva, Kalmanov filter, algoritmi IMM i GNN.

\title{
A STUDY OF A TARGET TRACKING METHOD USING GLOBAL NEAREST NEIGHBOR ALGORITHM
}

Summary:

This paper compares two algorithm for Multiple Target Tracking using Global Nearest Neighbor (GNN) approach: first by the use standard Kalman filter (SKF-GNN) and second by the use Interacting Multiple Model (IMMGNN) in order to derive final tracking estimation. For both algorithms the observations are divided in clusters to reduce computational efforts. Results of simulations by tracking 20 targets simultaeously reveal that in some cases the IMMGNN approach gives better soultion then KF-GNN approach. The computational time for assignment problem solution for maneuvering target tracking using both algorithm is studied and results prove that is IMMGNN suitable for real time imlementations.

Key words: multiple target tracking, data association, Global Nearest Neighbor.

\section{Uvod}

Proces kontrole vazdušnog saobraćaja obuhvata praćenje pokretnih ciljeva u okruženju gustog klatera. To su, pre svega, civilni avioni na redovnim destinacijama, ali i vojni avioni čiji su opseg manevra i brzina znatno veći. Kod vojnih borbenih aviona opterećenje $\mathrm{u}$ manevru dostiže vrednost do $7 \mathrm{~g}$, pa postoji opasnost da dođe do konfliktnih situacija. Rekurzivni postupak estimacije stanja (pozicije, brzine i ubrzanja) pomoću Kal- manovog filtera i interaktivnog višestrukog modela (IMM) detaljno je opisan u literaturi. Algoritmi za asocijaciju podataka koriste neke statističke parametre vektora stanja (statistička distanca, funkcija gustine verovatnoće, itd.), ali u osnovi poseduju filter za estimaciju vektora stanja cilja.

U ovom radu je izvršena analiza srednje kvadratne greške RMSE (Root Mean Square Error) kada se koristi algoritam „najbližeg suseda“ GNN (Global Nearest Neighbor) i procena potrošnje 
procesorskog vremena pri situaciji istovremenog praćenja 20 ciljeva u vazdušnom prostoru, pomoću osmatračkog radara TWS (Track While Scan) sa periodom $\mathrm{T}=10 \mathrm{~s}$. Predloženi algoritam koristi se u dve varijante: sa standarnim Kalmanovim filterom 6 . reda i algoritmom IMM (Interacting Multiple Model) sa tri Kalmanova filtera kao estimatorima stanja položaja, brzine i ubrzanja aviona. Praćenje se vrši u dvodimenzionalnom Dekartovom koordinatnom sistemu.

\section{Definisanje problema}

Ovaj rad predstavlja nastavak istraživanja opisanih u [4], gde su dati teorijski aspekti primene estimatora stanja $\mathrm{u}$ vidu Kalmanovog filtera i algoritma IMM, kao i postupak optimizacije parametara za primenu pri praćenju manevrišućih ciljeva pomoću osmatračkih radara. On treba da zaokruži celinu praćenja ciljeva, kroz konkretnu proveru rada estimatora, za koju je odabran scenario istovremenog praćenja 20 pokretnih ciljeva. Ažuriranje gejta sprovodi se po proceduri predloženoj u [6]. Sprovedene simulacije treba da budu komparativna analiza pomenutih algoritama, u smislu srednje kvadratne greške praćenja po poziciji i potrošnje procesorskog vremena, za slučaj praćenja standardnim Kalmanovim filterom ili IMM estimatorom.

Polazeći od dinamičkih jednačina stanja, koje se mogu modelovati kao:

$$
x(k+1)=F(k) x(k)+G(k) v(k)
$$

i jednačine merenja koja je data kao: $y_{j}(k)=H(k) x(k)+\omega(k), j=1,2, \ldots, m(k)$ pri čemu je:

$x(k)$ - vektor stanja cilja u k-tom skenu,

$y_{j}(k)$ - j-ta opservacija koja je primljena u k-tom skenu,

$F(k)$ - tranziciona matrica (matrica prelaza iz stanja u stanje),

$H(k)$ - matrica merenja (opservacija).

$v(k)$ - šum procesa $\mathrm{i}$

$\omega(k)$ - šum merenja, tj. nekorelisani beli

Gausov šum sa poznatom kovarijacionom matricom $\mathrm{R}$,

$G(k)$ - matrica šuma procesa $\mathrm{v}(\mathrm{k})$

$m(k)$ - broj merenja pristiglih u k-tom

skenu.

Odabiranjem modela filtera koji prati poziciju i brzinu cilja i praćenje cilja $u$ Dekartovom koordinatnom sistemu, matrice F, G, H dobijaju sledeće vrednosti:

$$
\begin{aligned}
& F=\left[\begin{array}{llll}
1 & T & 0 & 0 \\
0 & 1 & 0 & 0 \\
0 & 0 & 1 & T \\
0 & 0 & 0 & 1
\end{array}\right], G\left[\begin{array}{ll}
0 & 0 \\
1 & 0 \\
0 & 0 \\
0 & 1
\end{array}\right], \\
& H=\left[\begin{array}{llll}
1 & 0 & 0 & 0 \\
0 & 0 & 1 & 0
\end{array}\right]
\end{aligned}
$$

gde je sa $\mathrm{T}$ označena perioda skeniranja radara, dok je kovarijaciona matrica šuma merenja uzeta vrednost:

$$
R=\left[\begin{array}{cc}
\sigma_{x}^{2} & 0 \\
0 & \sigma_{y}^{2}
\end{array}\right]
$$

gde su $\sigma_{x}^{2}$ i $\sigma_{y}^{2}$ varijanse šma merenja za $\mathrm{x}$ i y koordinate, respektivno. 


\section{Opis algoritma „najbližeg suseda“}

Sistemi za praćenje pokretnih ciljeva u vazdušnom prostoru koriste estimatore stanja u situacijama kada se prati jedan cilj. Međutim, proces praćenja se komplikuje kada se u gejtu posmatranog traga nađu dva ili više ciljeva. Tada je neophodno koristiti algoritme za asocijaciju podataka. U ovom radu predložen je algoritam „najbližeg suseda“. Drugim rečima, ovaj algoritam predlaže da se posmatranom tragu dodeljuje ona opservacija iz skupa pristiglih opservacija koje su upale u gejt, čija je statistička distanca najmanja u odnosu na predikciju iz prethodnog skena.

Rad je zamišljen kao analiza greške u sistemima za praćenje pokretnih ciljeva u vazdušnom prostoru i odnosi se na dve kategorije algoritama: prvu kategoriju predstavlja kombinacija standardnog Kalmanovog filtera za estimaciju stanja i GNN algoritam za asocijaciju podataka; druga kategorija algoritama koristi kombinovanje IMM algoritma za estimaciju stanja i GNN algoritma za asocijaciju podataka.

Algoritmi za asocijaciju podataka, po pravilu, sadrže neki od filtera za estimaciju stanja. Na taj način moguće je napraviti poređenje ovih algoritama sa stanovišta srednje kvadratne greške praćenja po poziciji.

Kombinovanjem algoritama za estimaciju stanja (Kalmanov filter i interaktivni višestruki model) sa algoritmom za asocijaciju podataka („najbližeg suseda“) dobijene su dve klase algoritama za praćenje pokretnih ciljeva, koje će se proveriti tokom simulacija. Ovi algoritmi detaljno su opisani u [1, 2 i 4].
Za proces asocijacije podataka, kada se u gejtu nađe više od jedne opservacije, predložen je i ispitan algoritam najbližeg suseda (GNN - Global Nearest Neighbor). On je odabran zbog jednostavnosti i male potrošnje procesorskog vremena, a pokazao je dobre rezultate za primene $u$ kojima se koriste osmatrački radari sa periodama skeniranja većim od $\mathrm{T}=4 \mathrm{~s}$.

Algoritam ,najbližeg suseda“ predstavlja jednostavan pristup problemu praćenja ciljeva u okruženju klatera. On koristi standardni Kalmanov filter i, uzimajući „najbliže“" merenje unutar gejta, ažurira stanje položaja i kovarijacione matrice. Princip asocijacije podataka može se opisati sa tri moguća događaja:

$M_{T}$ - merenje potiče od cilja,

$M_{F}-$ merenje ne potiče od cilja,

$M_{0}$ - merenje nije validno (ne nalazi se u gejtu traga koji se prati).

Ovi događaji takođe se uzimaju u obzir pri derivaciji kovarijacione greške estimacije cilja. Osnovni koraci ovog algoritma su:

- korak predikcije: identičan je kao kod standardnog Kalmanovog filtera,

- korak ažuriranja stanja i kovarijacione matrice:

a) za slučaj $\mathrm{M}_{0}$, ako se sa $k$ označi redni broj skena,

$$
\begin{aligned}
& \hat{x}_{k}=\bar{x}_{k} ; \\
& \hat{P}_{k}=\bar{P}_{k}+\frac{P_{D} P_{G}\left(1-C_{\tau_{g}}\right)}{1-P_{D} P_{G}} K_{k} S_{k} K_{k}^{T}
\end{aligned}
$$

b) za slučaj $\overline{\mathrm{M}}_{0}$ 
$\hat{x}_{k}=\bar{x}_{k}+K_{k}\left(y_{k}-H_{k} \bar{x}_{k}\right)$;

$\hat{P}_{k}=\bar{P}_{k}-K_{k} S_{k} K_{k}^{T}$

pri čemu je:

$P_{D}$ - verovatnoća detekcije cilja,

$P_{G}-$ verovatnoća da se cilj nalazi unutar gejta,

$P_{G}=\frac{1}{2^{\frac{n}{2}} \Gamma\left(\frac{n}{2}\right)} \int_{0}^{\gamma} q^{\frac{n}{2}-1} e^{-\frac{q}{2}} d q$

$C_{\tau_{g}}$ - konstanta odnosa kovarijansi data kao:

$C_{\tau_{g}}=\frac{\int_{0}^{\gamma} q^{n / 2} e^{-q / 2} d q}{n \int_{0}^{\gamma} q^{\frac{n}{2}-1} e^{-q / 2} d q}$

gde je:

$-n=2$ (dvodimenzionalni prostor),

$-\sqrt{\gamma}$ - dimenzija gejta,

$-\Gamma\left(\frac{n}{2}\right)=2 \pi^{\frac{n}{2}} / n c_{n}$, dok je za

$c_{2}=2 \pi, c_{3}=\frac{4 \pi}{3}$.

$-q-$ vrednost vektora inovacije.

S obzirom na to da se radi o problemu 2D, navedeni izrazi se lako uprošćavaju. Pretpostaviće se da postoji set od $n$ tragova koji se istovremeno prate, dok je broj merenja (opservacija) koja pristižu u toku jedne periode obrta antene radara (skene) jednak m. U realnoj situaciji, kada se unutar seta opservacija, pored ciljeva, mogu naći odrazi koji potiču od kla- tera, jasno je da je $\mathrm{n}<\mathrm{m}$. Validna merenja su ona koja se nalaze unutar gejta ili na njegovim granicama. Matematički gejt može se definisati kao

$d_{i j}=\tilde{y}_{i j}^{T} S_{i}^{-1} \tilde{y}_{i j}<\gamma$

Vrednost parametra $\gamma$ bira se tako da se osigura opstanak merenja unutar gejta, sa određenom verovatnoćom [3]. Nejednačina (9) predstavlja test. Na osnovu literature [7] formira se matrica statističkih distanci između j-te opservacije i i-tog traga, $\mathrm{c}_{\mathrm{ij}}$ definisana kao:

$\left[c_{i j}\right]=\left[\begin{array}{llll}c_{11} & c_{12} & \ldots & c_{1 m} \\ c_{21} & c_{22} & \ldots & c_{2 m} \\ \ldots & & \ldots \\ c_{n 1} & c_{n 2} & \ldots & c_{n m}\end{array}\right]$

Elementi matrice poprimaju sledeće vrednosti:

$c_{i j}=\left\{\begin{array}{l}100, \text { ako se } j \text {-ta opservacija ne } \\ \text { nalazi unutar gejta i-tog skena } \\ d_{i j}^{2}, \text { ako se j-ta opservacija } \\ \text { nalazi unutar gejta i-tog skena }\end{array}\right.$

Problem se svodi na dodeljivanje tragu one opservacije koja ima minimalnu statističku distancu. Drugim rečima, traži se minimalna vrednost svake vrste matrice, a redni broj minimuma unutar vrste određuje opservaciju koja je pripala tragu. Ovaj način pridruživanja ne vodi računa o drugim statističkim parametrima vektora stanja tragova, kao što je funkcija gustine verovatnoće, pa ima određenih manjkavosti pri konkretnoj primeni u praksi. 


\section{Rezultati simulacije}

\section{Program realizacije simulacije}

Za simulaciju je izabran scenario kretanja aviona, kao što prikazuje slika 1 . Naime, istovremeno lete četiri grupe po pet aviona, a ukupno trajanje leta je 72 skena. Putanje su napadnute aditivnim Gausovim belim šumom, čija je srednja vrednost jednaka nuli. Standardna devijacija šuma procesa je $\sigma_{\mathrm{p}}=\mathrm{g} / 2, \mathrm{~g}=10 \mathrm{~m} / \mathrm{s}^{2}$, a standardna devijacija merenja po $\mathrm{x}$ i y koordinatama je $\sigma_{\mathrm{x}}=200 \mathrm{~m}, \sigma_{\mathrm{y}}=200 \mathrm{~m}$, respektivno, [2]. Verovatnoća detekcije cilja je 1.

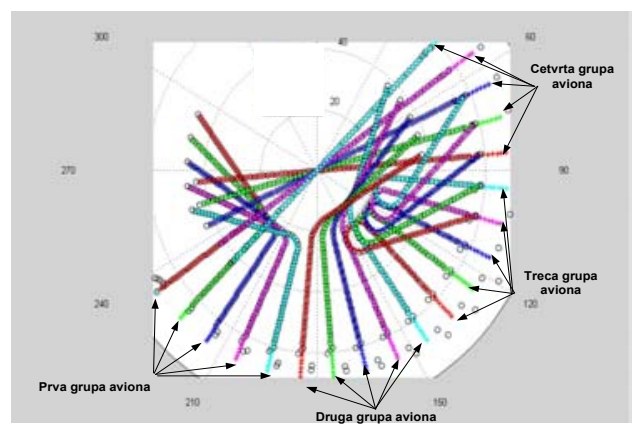

Sl. 1 - Simulacione trajektorije kretanja četiri grupe po 5 aviona
Prva grupa aviona leti pravolinijski, brzinom od $311 \mathrm{~m} / \mathrm{s}$, sve do 34 skena, kada vrši manevar od 2 g, u trajanju od 8 skenova. Druga i treća grupa aviona leti na isti način, ali brzinama od $341 \mathrm{~m} / \mathrm{s}$ i $371 \mathrm{~m} / \mathrm{s}$, respektivno, i vrednošću opterećenja u manevru od $1 \mathrm{~g}$ i $3 \mathrm{~g}$ respektivno. Četvrta grupa aviona leti pravolinijski brzinom od $401 \mathrm{~m} / \mathrm{s}$ bez manevra. Podaci o njihovom položaju dobijaju se sa radara čija je perioda odabiranja $\mathrm{T}=4 \mathrm{~s}$. Svi filteri podešeni su tako da prate poziciju i brzinu aviona. Cela simulacija urađena je na PC Pentium III, čiji procesor radi na $1200 \mathrm{MHz}$. U tabeli su navedeni parametri simulacije leta aviona za sve četiri grupe ciljeva.

Parametri simulacije leta aviona

\begin{tabular}{|c|c|c|c|c|c|}
\hline $\begin{array}{c}\text { Grupa } \\
\text { aviona }\end{array}$ & $\begin{array}{c}\text { Broj } \\
\text { aviona } \\
\text { u grupi }\end{array}$ & $\begin{array}{c}\text { Brzina } \\
\text { aviona } \\
{[\mathrm{m} / \mathrm{s}]}\end{array}$ & $\begin{array}{c}\text { Optere- } \\
\text { ćenje u } \\
\text { mane- } \\
\text { vru }\end{array}$ & $\begin{array}{c}\text { Trajanje } \\
\text { manevra } \\
{[\mathrm{T}]}\end{array}$ & $\begin{array}{c}\text { Ukupno } \\
\text { trajanje } \\
\text { leta }[\mathrm{T}]\end{array}$ \\
\hline Prva & 5 & 311 & $2 \mathrm{~g}$ & $\begin{array}{c}8 \\
(34-42)\end{array}$ & 72 \\
\hline Druga & 5 & 341 & $\mathrm{~g}$ & $\begin{array}{c}8 \\
(34-42)\end{array}$ & 72 \\
\hline Treća & 5 & 371 & $3 \mathrm{~g}$ & $\begin{array}{c}8 \\
(34-42)\end{array}$ & 72 \\
\hline Četvrta & 5 & 401 & - & - & 72 \\
\hline
\end{tabular}

b)

a)

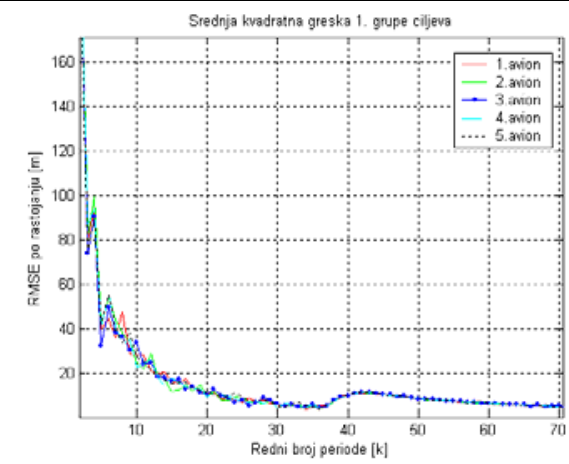

Sl. 2 - Srednja kvadratna greška za prvu grupu ciljeva a) GNN i b) IMM-GNN 


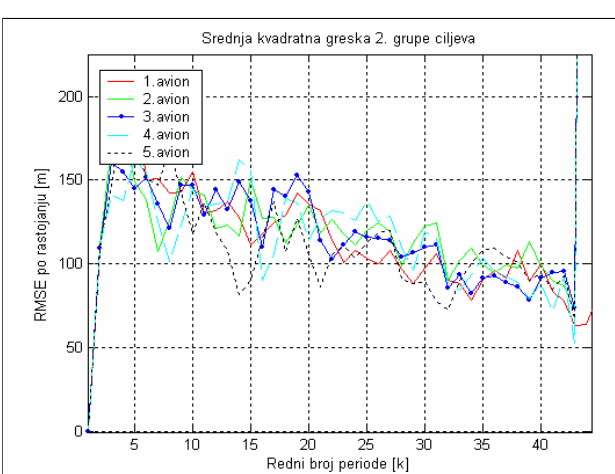

a)

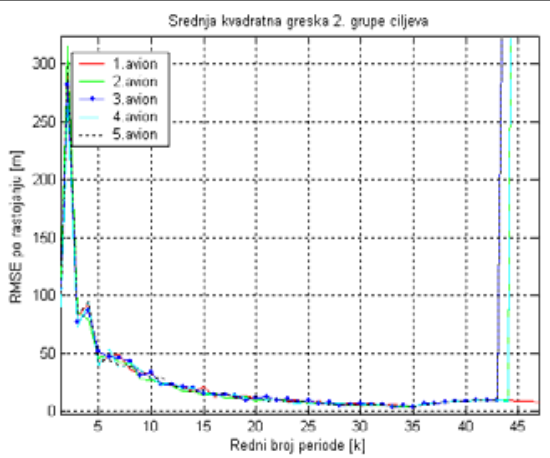

b)

Sl. 3 - Srednja kvadratna greška za drugu grupu ciljeva a) GNN i b) IMM-GNN

Tokom simulacije mereno je procesorsko vreme za algoritme GNN i IMMGNN. Algoritmi rade paralelno, pri čemu se smatra da je gejt posmatranog traga konstantan.

\section{Prikaz rezultata simulacije}

Rezultati simulacije dati su za sve pomenute klase algoritama. Sve kategorije rezultata prikazuju srednje kvadratne greške pozicije aviona za sve četiri grupe ciljeva na bazi 50 Monte Karlo prolaza, za pomenute klase algoritama. Na slikama 2, 3, 4 i 5 prikazani su rezultati srednje kvadratne greške po poziciji za algoritam, GNN i IMM-GNN algoritam za prvu, drugu, treću i četvrtu grupu aviona, respektivno. Uporednom analizom ovih grešaka može se uočiti da je IMM-GNN filter kvalitetniji i stabilniji, jer je manje „razbacivanje“ greške, ali je cena ovog poboljšanja visoka, jer je potrošnja procesorskog vremena veća.

Međutim, ovo poboljšanje odnosi se na situacije kada nema ukrštanja putanja

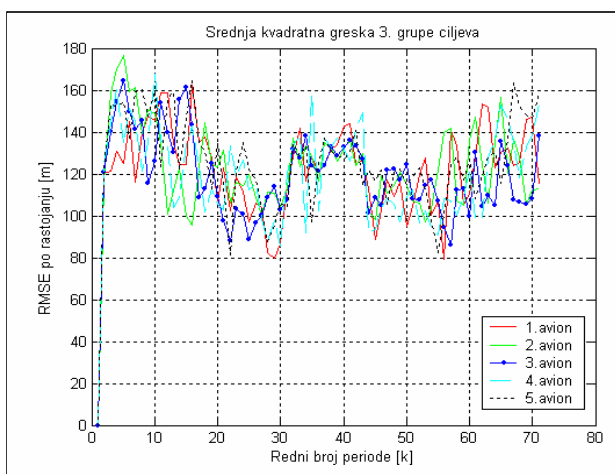

a)

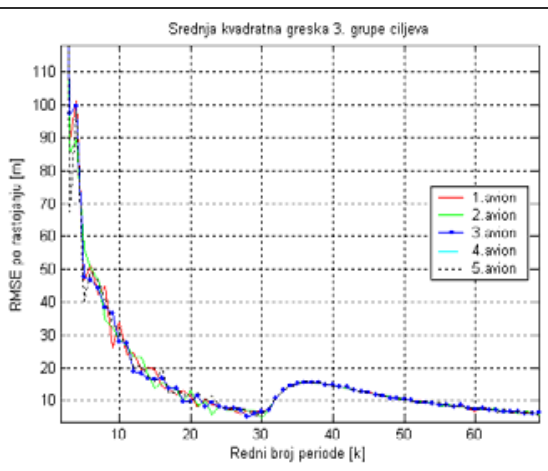

b)

Sl. 4 - Srednja kvadratna greška za treću grupu ciljeva: a) GNN i b) IMM-GNN 


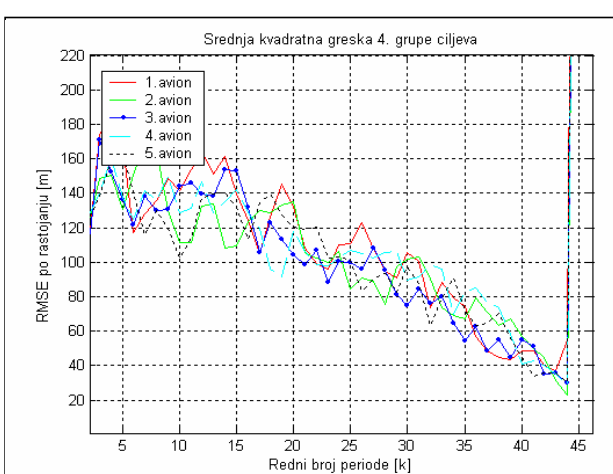

a)

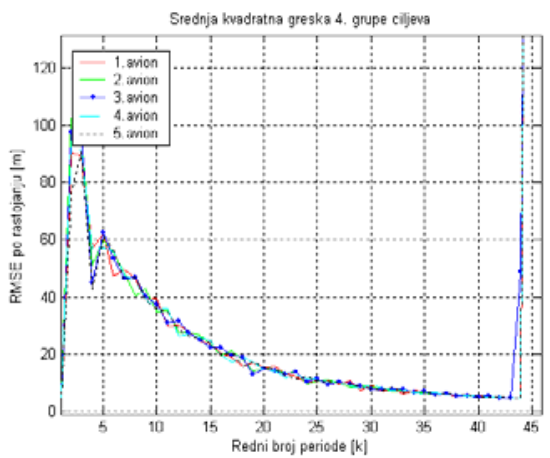

b)

Sl. 5 - Srednja kvadratna greška za četvrtu grupu ciljeva: a) GNN i b) IMM-GNN

aviona. Gubitak praćenja koji se ogleda u porastu srednje kvadratne greške (situacija posle 45. skena na slikama 3 i 5), potvrđuje činjenicu o nesigurnosti pomenutih testiranih algoritama asocijacije podataka. U slučajevima kada se ukrštaju dva ili više aviona dolazi do gubitka traga, pa se ne može govoriti o realnoj grešci, jer nije poznato koji se trag prati u odnosu na inicijalno stanje. Zato je potrebno izvršiti ponovnu inicijalizaciju tragova. Nova inicijalizacija tragova vrši se ukoliko se ne pojave tri opservacije u toku 5 uzastopnih skenova.

$\mathrm{Za}$ razliku od algoritma GNN, složeniji algoritam IMM-GNN ima znatno manje srednje kvadratne greške u delu gde nema gubitka cilja, ali posle ukrštanja putanja aviona greška se naglo povećava. Na taj način nameće se zaključak da treba tragati za kvalitetnijim algoritmima za asocijaciju podataka. To su, prvenstveno, klase algoritama za asocijaciju podataka po verovatnoći (PDA), kao i algoritmi sa formiranjem hipoteza (MHT), koji će biti predmet daljih istraživanja.

\section{Zaključak}

U radu su prikazani rezultati primene dve klase algoritama za praćenje ciljeva. Tokom simulacija zadate su realne putanje sa uticajem Gausovog belog šuma. Korišćena je metoda Monte Karlo za proračun srednje kvadratne greške. Rezultati simulacije pokazali su da je za praćenje ciljeva pomoću osmatračkog radara, u slučaju vojnih formacija, nedovoljno koristiti standardni GNN algoritam. Tada dolazi do ukrštanja putanja aviona, odnosno u gejtu traga nađe se više od dve opservacije. Pored toga, oseća se znatno povećanje računarskih resursa kada se koriste estimatori stanja složeniji od standardnog Kalmanovog filtera. Prikazani su rezultati srednje kvadratne greške za jednostavne algoritme za asocijaciju podataka. Oni su pokazali određene nedostatke za slučajeve manevrišućih ciljeva koji se kreću u formacijama.

U narednim istraživanjima treba proširiti simulacije za praćenje u prisustvu šuma, ali sa sofisticiranim metodama za asocijaciju podataka, kao što su PDA, IMMPDA, JPDA, IMMJPDA i MHT [8, 9, 10, 11]. 
Pored toga, istraživanja treba proširiti na situacije sa ažuriranjem dimenzija gejta, kao i sa grupama manevrišućih ciljeva koji imaju veće brzine i vrše oštrije manevre.

Literatura:

[1] Li, X. R., Shalom, Y. Bar: Design of Interacting Multiple Model Algorithm for Air Traffic Control Tracking 0147 IEEE Transactions on Control, Systems Technology, 1(3), 186-194, September 1993.

[2] Shalom, Y. Bar, Blair, W. D.: Multitarget-Multisensor Tracking: Applications and Advances-Volume III, Artech House, Norwood, MA 02062, 2000.

[3] Blackman, S.: Multiple-Target Tracking with Radar Applications, Artech House, Dedham, 1986.

[4] Blackman, S., Populi, R.: Design and Analysis of Modern Tracking Systems, Artech House, 1999.

[5] Radosavljević, Z.: Analiza primene IMM algoritma za praćenje manevrišućih ciljeva, Vojnotehnički glasnik, br. 3, juni, 2005.
[6] Lee, D. G., Song,T. L.: Perfomance Analysis of NNF-class Target Tracking Algorithms Applied to Benchmark Problem, Hanyang University Korea.

[7] Konstantinova, P. Udvarev, A., Semerdjiev, T.: A Study of a Target Tracking Algorithm Using Global Nearest Neighbor Approach, International Conference on Computer Systems and Technologies - CompSysTech'2003.

[8] Keuk, G.: Multihypothesis tracking using incoherent signalstrength information. IEEE Transactions on Aerospace and Electronics Systems, 32(3), pages 1164-1170, 1996.

[9] Feo, M., Graziano, A., Migliolo R., Farina, A.: IMMJPDA versus MHT and Kalman Filter with NN Corelation: Perfomance Comparision, IEEE Proceedings - Radar Sonar and Navigation, 144(2):49-56, April, 1997.

[10] Hadzagic, M., Mishalska, H., Jouan, A.: IMM-JVC and IMM-JPDA for closely maneuvering target, In Conference Record of the Thirty-Fifth Asilomar conference on Signals, Systems and Computers, Volume 2, pages 12781282, November, 2001.

[11] Gad, A., Farooq, M., Serdula J., Peters D.: Multitarget tracking in a multisensor multiplatform envirment, in Proc. of the 7th International Conference on Information Fusion, IF-0206, Stockholm, Sweden, 2004. 


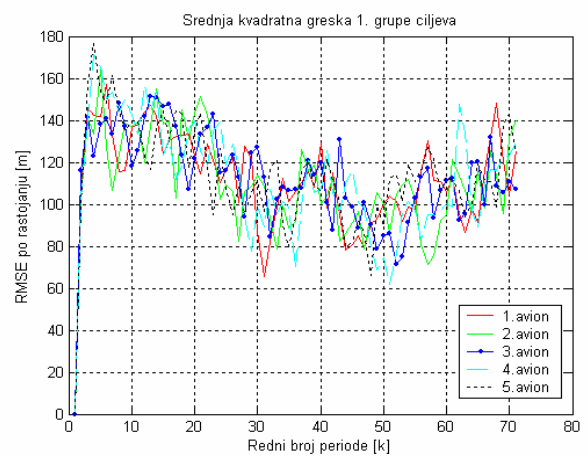

a)

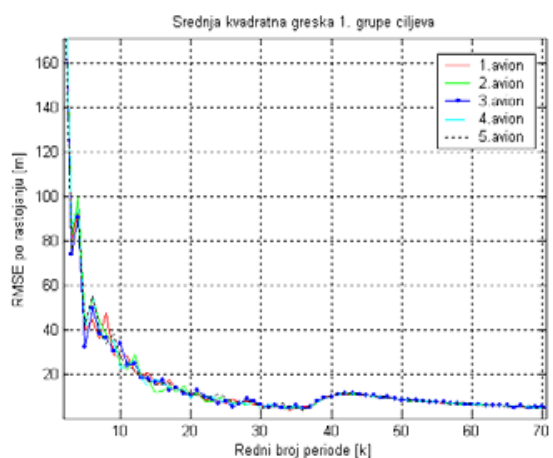

b)

Sl. 2 - Srednja kvadratna greška za prvu grupu ciljeva a) GNNi b) IMM-GNN

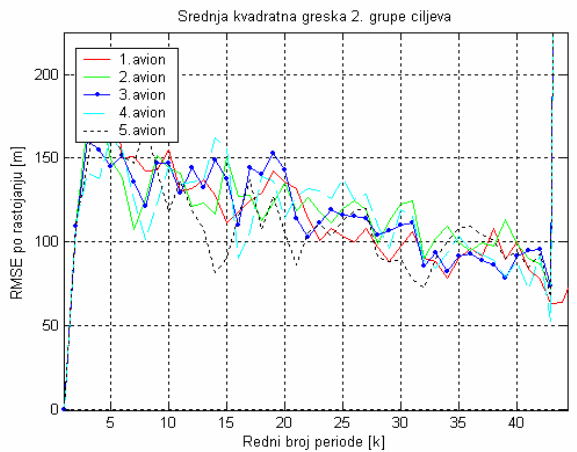

a)

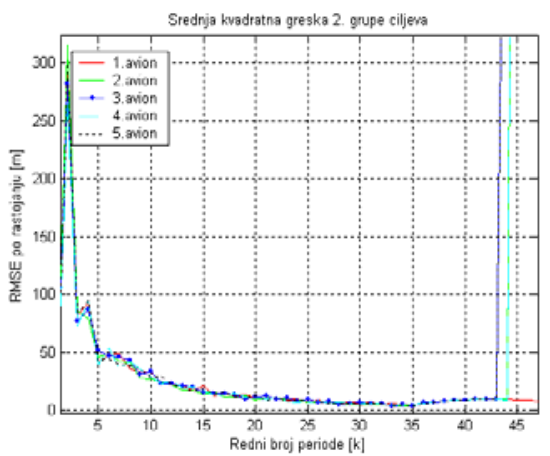

b)

Sl. 3 - Srednja kvadratna greška za drugu grupu ciljeva a) GNN i b) IMM-GNN

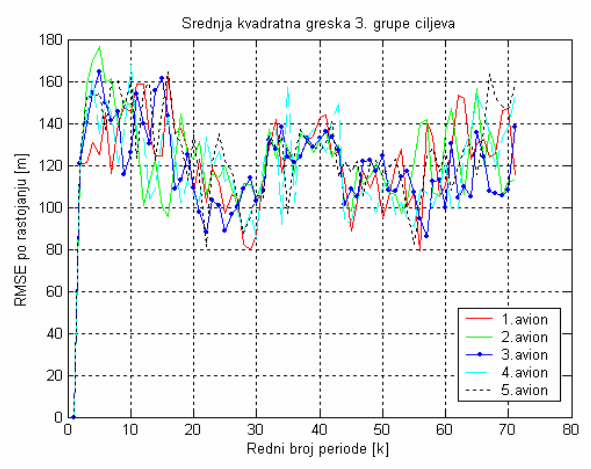

a)

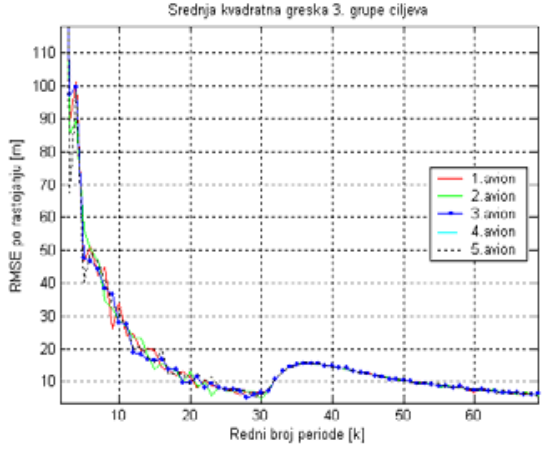

b)

Sl. 4 - Srednja kvadratna greška za treću grupu ciljeva: a) GNN i b) IMM-GNN 


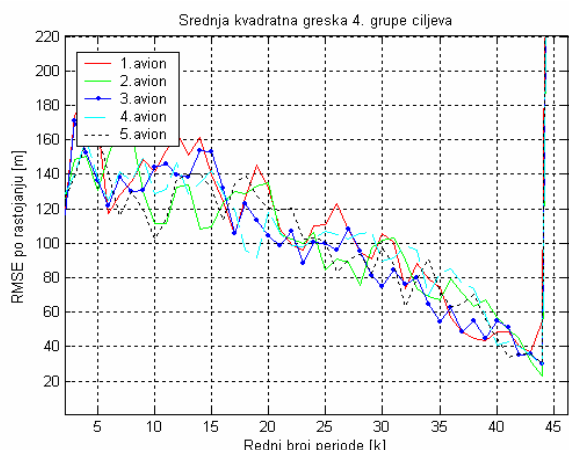

a)

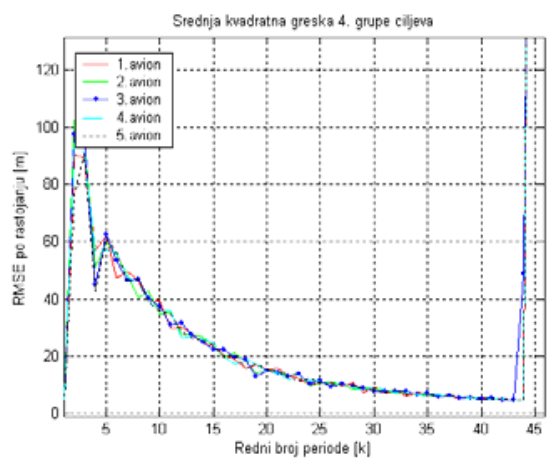

b)

Sl. 5 - Srednja kvadratna greška za četvrtu grupu ciljeva: a) GNN i b) IMM-GNN 